PACS 66.20.Ej, 72.15.Cz 82.60.-s, 64.60.F(c) 2011

\section{STUDY OF THE TRANSPORT \\ PROPERTIES OF THE CRITICAL BINARY MIXTURE TRIETHYLAMINE - WATER WITH AN IONIC IMPURITY}

\author{
A. TOUMI, ${ }^{1}$ N. HAFAIEDH, ${ }^{1}$ M. BOUANZ ${ }^{2}$ \\ ${ }^{1}$ Laboratoire de Physique des Liquides Critiques, Département de Physique \\ Faculté des Sciences de Bizerte Zarzouna 7021 Bizerte \\ Université de Carthage \\ TUNISIA \\ (e-mail: Adel. Toumi@fst. rnu.tn) \\ ${ }^{2}$ Laboratoire de Physique des Liquides et d'Optique Non Linéaire \\ Département de Physique, Faculté des Sciences de Tunis \\ Campus universitaire, El Manar 2092 Tunis \\ Université de Tunis El Manar \\ TUNISIA
}

The binary liquid mixture of triethylamine + water $($ TEA-W) has a lower consolute point at a critical composition of 32.27 mass. \% triethylamine. The shear viscosity $(\eta)$ and the electrical conductivity $(\sigma)$ in the single phase region of this system with added $\left(\mathrm{K}^{+}\right.$, $\mathrm{Cl}^{-}$) ions at various concentrations are measured in the vicinity and far from the critical temperature $T_{\mathrm{C}}$. For the pure system without $\mathrm{KCl}$ salt, the viscosity measurements yield an enhancement, as expected, for the Ising criticality with a crossover to a regular behavior. Shear viscosity data are consistent with a powerlaw divergence $\eta=\eta_{0}\left(Q \zeta_{0}\right)^{z} t^{-y}$ predicted by the mode-coupling and dynamic renormalization group theories. In the temperature range $\Delta T=T_{\mathrm{C}}-T<2{ }^{\circ} \mathrm{C}$, the electrical conductivity $(\sigma)$ exhibits a monotonous deviation from the Vogel-Fulcher-Tammann (VFT) behavior. This anomaly is described by a power law $t^{1-\alpha}$, where $t$ is the reduced temperature $\left|\frac{T-T_{\mathrm{C}}}{T_{\mathrm{C}}}\right|$, and $\alpha$ is the critical exponent of the specific heat anomaly at constant pressure. For the electrolyte mixtures, the obtained critical exponent values are in the range of those expected by the theoretical calculations for the Ising 3D universality class. By combining the viscosity and the electrical conductivity data, the value of the computed Walden product has been determined, and the salt dissociation degrees, as well as the Debye screening length, have been estimated.

\section{Introduction}

The transport properties of binary liquids exhibit intriguing anomalies near a consolute point which are pre- sumably due to the presence of large critical fluctuations in the concentration. The impurity effects on the critical behavior of binary liquid mixtures have been of an experimental continuing interest and of great fundamental practical importance and received a great deal of attention [1-3], since the importance of such investigations extends into both theoretical and practical fields. The influence of ionic impurities is known to significantly affect both the temperature and the concentration of the critical point $[4,5]$. It modifies the behavior of several thermodynamic and transport properties. Researchers have also used impurities to shift the critical point when measuring the surface wetting $[6,7]$.

The present work is a continuation of our earlier studies on binary liquid systems that split into two phases from a single phase upon changing the temperature. Here, we continue our study of the binary mixture triethylamine + water $($ TEA-W) $[8,9]$. This mixture is very interesting from an experimental, as well as theoretical, point of view because it is known to be a typical partially miscible system that has a lower critical solution temperature (LCST) that splits into two phases with increase in the temperature. The LCST and the critical concentration of TEA are $18.4^{\circ} \mathrm{C}$ and 32.1 wt.\%, respectively [10]. It is widely believed that the hydration, which is a kind of hydrogen bond readily destroyed by heat, plays a prominent role in this phase behavior. 
Furthermore, trialkylamines are industrially important liquids [11] that are used as intermediates in the production of polymers such as phenolic resins, agrochemicals, pharmaceuticals, paints...

Viscosity is a very important physical property of fluids in the design of processes with fluid transport not only through pipes but also through pore surfaces and in many processes involving mass and energy transfer. Indeed, viscosity is a fundamental characteristic of substances such as adhesives, lubricants, paintings, and so forth. Furthermore, the electrical conductivity investigation represents a simple, accurate, and reliable method to study the solvents effects, modification in the structure of a solvent due to the presence of an ion and the ionic movement in a solution. The influence of various temperatures on conductivity measurements can give detailed information on the ion-ion and ion-solvent interactions for various solutions of electrolytes [12-15]. Although the critical (TEA-W) system has been the subject of some interest in the past [16-20], there is no investigation, to our knowledge, made for the effect of ions at weak concentrations on the transport properties of the critical (TEA-W) binary liquid mixture before this study. This prompted us to carry out precise measurements of the corresponding shear viscosity and electrical conductivity at the atmospheric pressure in a neighborhood of the critical temperature $T_{\mathrm{C}}$ and relatively far from this temperature in the single-phase region $(T<$ $T_{\mathrm{C}}$ ). Here, we report, in the single phase region, the experimental measurements of both the shear viscosity and the specific electrical conductivity of three concentrated binary ionic mixtures of $(\mathrm{TEA}-\mathrm{W})$ with $\mathrm{X} \mathrm{M}[\mathrm{KCl}]$ at critical concentration (here $\mathrm{X}$ stands for the molality of the electrolyte: moles of electrolyte per kilogram of solution). From our work, we can study the thermodynamic behavior of (TEA-W) with X M $[\mathrm{KCl}]$ close and far away from the critical point. Then, we try to inspect the ionic effect on the behavior of the mentioned transport properties, and we attempt to determine the salt degree of dissociation for the critical mixture by the help of the Walden product [21] computed near the critical temperature. It should be mentioned that the critical parameter $T_{\mathrm{C}}$ was identified visually in our laboratory to be $T_{\mathrm{C}}=291.426 \mathrm{~K}$ when the critical opalescence was well developed) at the critical composition $C_{\mathrm{C}}=32.1 \%$ of TEA mass fraction.

This paper is organized as follows. Section 2 is concerned with the experimental methods used in this work. The data collection and analysis techniques we used are treated in Section 3, and conclusions are given in Section 4 .

\section{Experimental}

\subsection{Materials}

Triethylamine (TEA) was purchased from Prolabo. The purity was stated to be $99.95 \mathrm{~mol} \%$. Additional purification has not been considered necessary. The main impurity is probably water. The water used in this study was obtained from deionized and three-time distilled operations. The guaranteed purity of the $\mathrm{KCl}$ salt (Merck) is better than $99.5 \%$.

\subsection{Apparatus and procedure}

The weight was performed by using a digital electronic balance (Sartorius BP 221S) with an uncertainty of $10^{-4}$ g. Some care was taken to avoid moisture and dust in the final sample, namely, baking the syringes and the cells overnight under vacuum and preparing the mixtures in a dust-free area. The mole fraction was accurate up to the fourth place of decimal. The cell, in which TEA and water were mixed together, was immersed in a thermally stabilized water bath with thermal regulation on the order of $0.002 \mathrm{~K}$ over hours. We measured the temperature by using a quartz thermometer (HP2804A) giving an uncertainty of $0.001 \mathrm{~K}$ that was calibrated on an absolute scale within $0.01 \mathrm{~K}$.

The mass density data were carried out by measuring the density $\rho \mathrm{g} \cdot \mathrm{cm}^{-3}$ ) for the homogeneous phase. Measurements have been performed with an Anton Paar digital precision densimeter with an accuracy of $\pm 0.01 \mathrm{~K}$. This apparatus needs to be carefully calibrated with two liquids of different densities; we choose water and methanol, with density data from [22]. In order to avoid systematic errors while measuring the densities of pure liquids at different temperatures, each temperature change was followed by a waiting time of two hours. The precision of density measurements was $\pm 0.0001 \mathrm{~g} \cdot \mathrm{cm}^{-3}$.

The kinematic viscosities $(\nu)$ of the (TEA-W) mixtures were measured with an (AVS/N-Schott-Greäte) Ubbelhode viscometer suspended in a thermostatically controlled water bath at a required temperature. The viscometer was calibrated using viscosity values taken from the known values for methanol and water [22]. An average of four or five sets of flow times were taken for each liquid and liquid mixture. The measured values of kinematic viscosities $(\nu)$ were converted to dynamic viscosities $(\eta)$ after multiplication by the density $(\rho)$. The flow-time measurements were made with an electronic stop watch having a precision of $\pm 0.01 \mathrm{~s}$. Viscosity values are accurate within the range $\pm 0.003 \mathrm{mPa} \cdot \mathrm{s}$. 


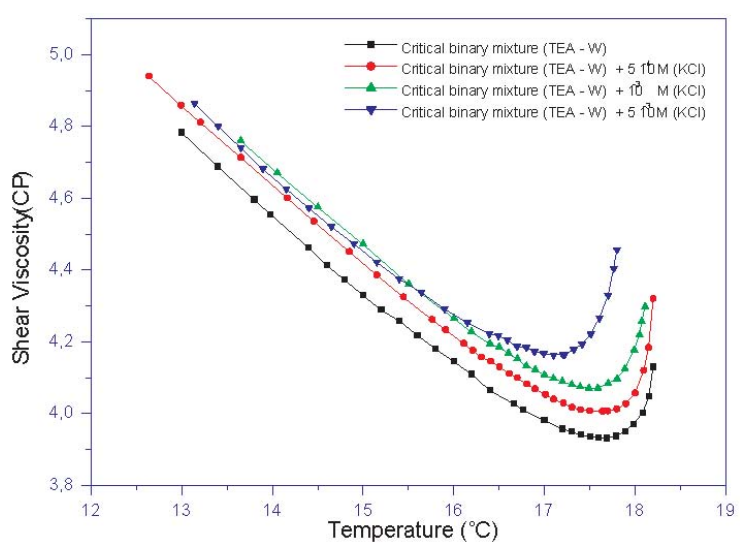

Fig. 1 Shear viscosity curves for the critical binary liquid TEAWater and for the critical binary liquid TEA-Water with successive amounts $\mathrm{X}$ of $(\mathrm{KCl})$. $\mathrm{X}$ is the salt concentration

The electrical conductivity $\left(\sigma, \mathrm{mS} \cdot \mathrm{cm}^{-1}\right)$ measurements were carried out using a Phywe conductometer having a precision of $0.10 \%$ and using a conductivity cell with fixed spacing stainless-steel circular electrodes. The calibration of the cell was made by using a $\mathrm{NaCl}$ solution with known electrical conductivity. The cell containing the solution was immersed in the above-mentioned thermally stabilized bath. In order to obtain consistent values, we held the temperature constant throughout each set of measurements and repeated every experiment three times under the same conditions.

The specific molar conductance $\left(\Lambda, \mathrm{S} \cdot \mathrm{cm}^{2} \cdot \mathrm{mol}^{-1}\right)$ of the solutions of salts under investigation were measured using Eq.(1):

$\Lambda=\frac{\sigma}{C}$.

Here, $C$ is the normal concentration, $\sigma$ is the measured specific conductivity of the studied solution, from which the specific conductivity of the relevant solvent medium was subtracted. Therefore, the solutions molalities are converted to molarities by using the relationship

$C=X \rho$

\section{Data Collection and Analysis}

We have determined the shear viscosity $(\eta)$ and the electrical conductivity $(\sigma)$ versus temperature $T$ of four different solutions: the critical binary liquid (TEA-W), $(\mathrm{TEA}-\mathrm{W})+5 \times 10^{-4} \mathrm{M}[\mathrm{KCl}],(\mathrm{TEA}-\mathrm{W})+10^{-3} \mathrm{M}$ $[\mathrm{KCl}]$ and $\left.(\mathrm{TEA}-\mathrm{W})+5 \times 10^{-3} \mathrm{M}[\mathrm{KCl}]\right)$ in the temperature range below $T_{\mathrm{C}}$. The higher limit was considered

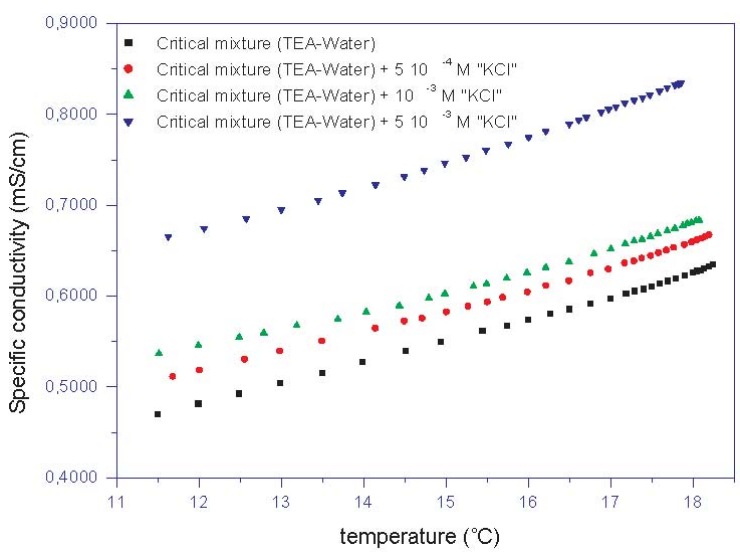

Fig. 2 Electrical conductivity curves for the critical binary liquid TEA-Water and for the critical binary liquid TEA-Water with successive amounts $\mathrm{X}$ of $(\mathrm{KCl})$

adequate for the main purpose of this study. Data were taken at the lower temperature in order to establish the temperature dependence of these transport properties well away from $T_{\mathrm{C}}$. In Figs. 1 and 2, we respectively show the shear viscosity and the electrical conductivity data versus the temperature for the investigated systems.

\subsection{Pure critical system (TEA-Water)}

\subsubsection{Shear viscosity}

Classical theory of transport properties assumes that viscosity for pure fluids or binary mixtures is not affected by long-range correlations near the critical point. Close to this point, the renormalization group [23] and modecoupling $[24,25]$ theories predict, in the hydrodynamic limit, that the shear viscosity $\eta$ will diverge as

$\eta=\eta_{0}(Q \zeta)^{z}$

where $\eta_{0}$ is the noncritical background viscosity, $\zeta$ is the correlation length, $Q$ is a system-dependent inverse length, and $z$ is the universal dynamic critical exponent, which has the same value for all systems belonging to the same dynamic universality class. The most accurate theoretical calculations for the Ising 3D universality class have yielded $z=0.068[26,27]$. At the critical concentration, the temperature dependence of the correlation length can be described by

$\zeta=\zeta_{0} t^{-\nu} F^{\prime}$,

where $t=\frac{T_{\mathrm{C}}-T}{T_{\mathrm{C}}}$ is the reduced temperature, $T_{\mathrm{C}}$ is the critical temperature, $\zeta_{0}$ is the correlation length amplitude, $\nu$ is the critical exponent of the correlation length, 
T a b l e 1. Parameter values obtained from the best fit of experimental data to Eq. (7). The values in brackets are fixed parameters

\begin{tabular}{|c|c|c|c|c|}
\hline$A /\left(10^{-8} \mathrm{cP}\right)$ & $B / K$ & $\Delta$ & $a$ & $y$ \\
\hline $15.07 \pm 1.62$ & $4901.88 \pm 29.10$ & $(0.5)$ & (0) & $0.0360 \pm 0.0005$ \\
\hline $18.40 \pm 1.07$ & $4840.40 \pm 16.92$ & $0.075 \pm 0.017$ & $0.075 \pm 0.017$ & $0.0373 \pm 0.0024$ \\
\hline $21.09 \pm 2.07$ & $4802 \pm 27.83$ & $(0.7)$ & $0.161 \pm 0.043$ & $0.0368 \pm 0.0017$ \\
\hline
\end{tabular}

and $F^{\prime}$ is a crossover function. By choosing a Wegner expansion [28] for the correlation length, we can write $F^{\prime}$ as

$F^{\prime}=1+a t^{\Delta}+\ldots$

With $\Delta=0.5$, the universal Wegner exponent, and $a$, a system-dependent correction-to-scaling amplitude, Eq. (3) can be expressed as

$\eta=\eta_{0}\left(Q \zeta_{0}\right)^{z} t^{-z \nu}\left(1+a t^{\Delta}+\ldots\right)^{z}$

Dynamic renormalization group correction-to-scaling $[29,30]$ of the transport coefficients gives the following expression for the shear viscosity:

$\eta=\eta_{0}\left(Q \zeta_{0}\right)^{z} t^{-y}\left(1+a^{\prime} t^{\Delta^{\prime}}+\ldots\right)$

where $\Delta^{\prime}$ is an effective exponent $\approx 0.7$. In general terms, in a vicinity of the critical point, the viscosity can be written in the form

$\eta=\eta_{0}\left(Q \zeta_{0}\right)^{z} t^{-y} F$

with $F$ is the crossover function of the viscosity, $y=z . \nu$ is the viscosity anomaly critical exponent, and $\nu=0.63$ is the correlation length exponent [31].

Several previous experimental studies of the viscosity at the liquid-liquid critical points in many different mixtures have been made. A considerable scatter in the values of the critical exponent $y$ over the last years has been showed by Sengers' study [32]. Berg and Moldover [33] have measured the shear viscosity in several binary mixtures and analyzed the data to determine $y$. They concluded that $0.0404 \leqslant y \leqslant 0.0444$. Moreover, by the data analysis of seven binary liquids with the same considerations made by Berg and Moldover, Nieuwoudt and Sengers [34] found that $y$ is close to 0.041. It is worth noting that more recent theoretical calculations for the Ising 3D universality class have yielded a value $y=0.0435[26,27]$ confirmed by the experimental value $y=0.044$ from experiments in a low-gravity environment [35].

In Fig. 1, we can observe the temperature dependence of the shear viscosity of the binary system (TEA-Water) at the critical concentration. As it is characteristic of the viscosity near a lower critical point solution, its value shrinks while lowering the temperature, showing essentially Arrhenius-type behavior. While approaching the critical point, the critical fluctuations cause a further increase of the viscosity: the critical divergence. Shear viscosity data are fitted by Eq. (7) using the Arrhenius law procedure in the fitting of the background contribution $\eta_{0}$ :

$\eta_{0}=A \exp \left(\frac{B}{T}\right)$

The function $F$ is set to 1 (no crossover) or corresponding to the first term of the Wegner correction-to-scaling for the correlation length.

$F=\left(1+a t^{\Delta}+\ldots\right)^{y / \nu}$

Table 1 shows various values for the viscosity anomaly critical exponent obtained by using the Arrhenius background. The critical exponent $y$, found in the range $0.0360 \leqslant y \leqslant 0.0368$, has been in good agreement with the different equations of the mode-coupling and dynamic renormalization group theories. This fact shows the accuracy of the presented methodology.

\subsubsection{Electrical conductivity}

Both the Arrhenius and Vogel-Fulcher-Tammann (VFT) equations are used to explain the temperature behavior of different physical magnitudes, such as the electrical conductivity. The VFT equation which is the most general law appears in different forms depending on the reference used $[36,40]$. Here, we have chosen the simplest and most usual form, which reads similar to

$\sigma=A^{\prime} \exp \left(-\frac{B^{\prime}}{T-T_{g}}\right)$,

where $A^{\prime}, B^{\prime}$ and $T_{g}$ are fitting parameters. If we fit the binary (TEA-W) experimental data to the VFT equation given by Eq. (11), we obtain a very fine fit with small values of standard errors. Subsequently, we can notice that the VFT law describes correctly the electrical conductivity in a temperature interval far from the critical temperature. The values of the parameters $A^{\prime}, B^{\prime}$ and $T_{g}$ are, respectively, $3.859 \pm 0.158$ 
T a b l e 2. Parameters of Eq. (13) describing the electrical conductivity of the critical binary liquid (TEA-W)

\begin{tabular}{c|c|c|c}
\hline$\sigma_{0}$ & $T_{\mathrm{c}}\left({ }^{\circ} \mathrm{C}\right)$ & $\alpha$ & $B_{\text {crit }}$ \\
\hline$-0.085 \pm 0.006$ & $18.279 \pm 0.013$ & $(0.109)$ fixed & $0.062 \pm 0.004$ \\
$-0.086 \pm 0.005$ & $18.308 \pm 0.093$ & $0.108 \pm 0.093$ & $0.063 \pm 0.005$ \\
\hline
\end{tabular}

$\mathrm{mS} / \mathrm{cm} ; 98.979 \pm 3.650 \mathrm{~K}^{-1}$, and $241.924 \pm 0.839 \mathrm{~K}$. Close to $T_{\mathrm{C}}$, the conductivity deviates slightly from the regular VFT behavior. This deviation becomes larger as the temperature of the mixture approaches the demixing temperature and might be interpreted as an anomaly of the electrical conductivity [41].

Near the critical point, the temperature dependence of the specific electrical conductivity reads [42]

$\sigma=\sigma_{\mathrm{VFT}}+\sigma_{\text {crit }}$

where

$\sigma_{\text {crit }} \approx \sigma_{0} t^{1-\alpha}+B_{\text {crit }}$

is the critical contribution. The critical exponent $\alpha=$ 0.109 is that of the specific heat anomaly at constant pressure, $\sigma_{0}$ and $B_{\text {crit }}$ are, respectively, the critical amplitude and the critical fluctuation-induced additive constant. In the temperature range $t<10^{-4}$, a slope close to $(1-\alpha)$ can fit the data. The value of $\sigma_{0}$ and $B_{\text {crit }}$ were determined by fitting the data to Eq. (13) in the studied temperature interval. Table 2 gives the values of $\sigma_{0}$ and $B_{\text {crit }}$. The value obtained for the exponent $\alpha=0.108 \pm 0.093$ is in agreement with renormalization group calculations [43] which estimate this critical exponent for the three-dimensional Ising universality class $(\alpha=0.1096 \pm 0.0005)$.

\section{2. $\left(\mathrm{K}^{+}, \mathrm{Cl}^{-}\right)$ions effect on the transport properties of the critical binary mixture ( $T E A-W a t e r)$}

\subsubsection{Shear viscosity of the critical binary fluid (TEA-W) with added $\left(\mathrm{K}^{+}, \mathrm{Cl}^{-}\right)$ions}

Figure 1 shows the shear viscosities of the critical binary liquid (TEA-W) with successive $\mathrm{KCl}$ salt concentrations: $5 \times 10^{-4} \mathrm{M}, 10^{-3} \mathrm{M}, 5 \times 10^{-3} \mathrm{M}$. The temperature dependence is similar in all cases. The viscosity of every mixture with $\mathrm{KCl}$ salt added has the same behavior as well as the pure critical mixture (TEA-W), the viscosities become at first smaller with increase in the temperature showing essentially the Arrhenius-type behavior. While approaching the critical point, the critical fluctuations cause an increase of the viscosity. The critical divergence of the viscosity is observed for all concentrations of the salt investigated. The added ions cause also an increase of the viscosity. The critical divergence and, hence, the minimum of the viscosities are shifted to lower temperatures by the salt. This fact seems to be a result of solvation effects. In the electrolyte solutions, we have two types of interactions: the moderate long-range effective dipole-dipole interactions and the strong ion-ion and ion-solvent interactions. The effective ion-ion interaction in such complex solvent as water results from cooperation and cancellation of many terms. Water should behave as a dielectric at larger ion-ion separations; while at shorter separations, the ion-water interaction becomes important [44]. The effect of the dielectric constant on the ionic mobility in mixed solvents has demonstrated that the dielectric relaxation in polar solvent induced by ionic movement gives rise to frictional resistance to that motion [45].

In Table 3, we include the fitting parameters, as described below in Eq. (7). Using the Arrhenius background, the obtained critical exponent $y$ for all mixtures with added ions which are in the range $0.038 \leqslant$ $y \leqslant 0.0446$ are in agreement with the theoretical estimation for binary mixtures. According to the contemporary comprehension of intermolecular interactions, the molecules are viewed as bodies made up of individual atoms or groups of atoms that are the seat of two types of interactions: (1) non-electrostatic (non-el) interactions generating a strong repulsion at short separations and a weak (van der Waals) attraction at medium separations, and (2) the long-range Coulombic charge-charge interactions. The latter interactions play a dominant role in driving a system to the mean-field critical behavior. Nevertheless, it is confirmed that the liquid-liquid phase transitions driven by short range interactions belong to the Ising universality class [43]. In fact, by assuming only next neighbor interactions, the Ising model neglects particular details concerning the structure of mixtures. For our electrolyte mixtures, due to charge ordering already described by the classical Debye-Hückel theory [46], the solvent is assumed to form a continuum background, where the ions are immersed, and the degrees of freedom of the solvent awesomely dominate that of the ions. Moreover, in electrolyte solutions, the strength of the Coulomb interactions depends on the dielectric constant $\varepsilon$ of the solvent. The high value of the dielectric constant of water $(\varepsilon=80)$ and the small amount of salts in the solutions lead to reduce the Coulombic force effect in front of the hydrogen bonds. 
T a b l e 3. Parameter values obtained from best fit of experimental data to Eq. (7). The values in brackets are fixed parameters

\begin{tabular}{|c|c|c|c|c|}
\hline$A /\left(10^{-8} \mathrm{cP}\right)$ & $B / K$ & $\Delta$ & $a$ & $y$ \\
\hline \multicolumn{5}{|c|}{$(\mathrm{TEA}-\mathrm{W})+5 \times 10^{-4} \mathrm{M}(\mathrm{KCl})$} \\
\hline $16.33 \pm 1.03$ & $4877.30 \pm 13.35$ & $(0.5)$ & $(0)$ & $0.0394 \pm 0.0007$ \\
\hline $14.52 \pm 1.42$ & $4913.14 \pm 31.11$ & $(0.5)$ & $-0.036 \pm 0.005$ & $0.0389 \pm 0.0005$ \\
\hline $11.41 \pm 0.93$ & $4979 \pm 19.46$ & $(0.7)$ & $-0.052 \pm 0.008$ & $0.0403 \pm 0.0006$ \\
\hline \multicolumn{5}{|c|}{$(\mathrm{TEA}-\mathrm{W})+10^{-3} \mathrm{M}(\mathrm{KCl})$} \\
\hline $33.79 \pm 1.78$ & $4669.64 \pm 17.98$ & $(0.5)$ & $0.073 \pm 0.002$ & $0.0394 \pm 0.0003$ \\
\hline $35.63 \pm 1.34$ & $3973.92 \pm 25.77$ & $(0.7)$ & $1.193 \pm 0.004$ & $0.0423 \pm 0.0006$ \\
\hline \multicolumn{5}{|c|}{$(\mathrm{TEA}-\mathrm{W})+5 \times 10^{-3} \mathrm{M}(\mathrm{KCl})$} \\
\hline $28.31 \pm 3.51$ & $4717.67 \pm 32.01$ & $(0.5)$ & $(0)$ & $0.0451 \pm 0.0006$ \\
\hline $81.20 \pm 8.90$ & $5084.38 \pm 29.10$ & $(0.5)$ & $-0.209 \pm 0.003$ & $0.0446 \pm 0.0005$ \\
\hline $21.96 \pm 2.66$ & $5465.63 \pm 26.88$ & $(0.7)$ & $-0.856 \pm 0.006$ & $0.0443 \pm 0.0006$ \\
\hline
\end{tabular}

\subsubsection{Walden Product}

As depicted in Fig. 2, the critical divergence of the electrical conductivity of the critical binary mixture (TEAW) with added $\left(\mathrm{K}^{+}, \mathrm{Cl}^{-}\right)$is seemingly not observed. Therefore, the electrical conductivity data for all ionic systems can be fitted with high precision with a VFTtype equation, Eq. (11). In Table 4, we include the corresponding fitting parameters. The largest value of $B^{\prime}$ is observed for the pure critical binary (TEA-W). According to [47], a decrease of the parameter $B^{\prime}$ is generally observed in less structured solvents [41]. The decrease of $B^{\prime}$ observed for ionic liquids could be attributed to the breakdown of the H-bond network because of the increasing number of hydrophobic $\mathrm{K}^{+}$cations.

For further exploration for the behavior of our studied mixtures, we have tried to determine the degree of dissociation $\alpha_{\text {diss }}$ of $\mathrm{KCl}$ salt in a solvent by combining both their shear viscosity and electrical conductivity data. Indeed, the linear dependence of the Walden product with the salt concentration is therefore related to the free ion concentration in the solution. This allows us to determine the dissociation constant $\alpha_{\text {diss }}$ according to [48]:

$\alpha_{\text {diss }}=\frac{\Lambda \eta}{(\Lambda \eta)_{0}}$

where $\eta$ and $\Lambda$ are, respectively, the viscosity and specific molar conductance of the solution and subscript " 0 " refers to infinite dilution of the ions. Figure 3 shows the variation of the Walden product $(\Lambda \eta)$ as a function of the temperature for the ionic mixtures. We can notice that, near the critical temperature $T_{\mathrm{C}}$, the Walden product value diminishes, as the $\mathrm{KCl}$ salt concentration
T a b l e 4. Theoretical physical magnitudes extracted from the best fit of experimental data to the VTF-type Eq. (11)

\begin{tabular}{lcccc}
\hline \multicolumn{1}{c|}{ System } & $A^{\prime}(\mathrm{ms} / \mathrm{cm})$ & $B^{\prime}\left(\mathrm{K}^{-1}\right)$ & $T_{g}\left({ }^{\circ} \mathrm{C}\right)$ \\
\hline Critical mixture & 3.477 & 87.563 & -34.011 \\
"TEA-W" & \pm & \pm & \pm \\
$+5 \times 10^{-4} \mathrm{M} \mathrm{KCl}$ & 0.241 & 6.577 & 0.714 \\
& & & \\
Critical mixture & 3.365 & 86.616 & -33.946 \\
"TEA-W" & \pm & \pm & \pm \\
$+10^{-3} \mathrm{M} \mathrm{KCl}$ & 0.601 & 11.324 & 0.654 \\
Critical mixture & 3.477 & 75.016 & -33.649 \\
"TEA-W" & \pm & \pm & \pm \\
$+5 \times 10^{-3} \mathrm{M} \mathrm{KCl}$ & 0.569 & 16.128 & 0.501 \\
\hline
\end{tabular}

increases, indicating that the degree of dissociation of the salt is reduced. Moreover, heating the electrolyte system leads to a decrease of the Walden product. This fact is due to a decrease in the viscosity which overweighs the effect of conductivity. It is worth noting that the increased values of Walden product indicate a weak solvation, while the decreased values of Walden product indicate a strong solvation [49]. Knowing that near the (TEA-W) critical temperature $T_{\mathrm{C}}$, the specific molar conductance $\Lambda_{0}$ of the salt potassium chloride $\mathrm{KCl}$ $\Lambda_{0}$ value is $149.79 \mathrm{~S} \cdot \mathrm{cm}^{2} \cdot \mathrm{mol}^{-1}[22]$, the $\alpha_{\text {diss }}$ values of the investigated mixtures, evaluated at the temperature $T=17.857^{\circ} \mathrm{C}$ (close to $T_{\mathrm{C}}$ ) are $0.92,0.70$, and 0.62 for $5 \times 10^{-4} \mathrm{M}, 10^{-3} \mathrm{M}$, and $5 \times 10^{-3} \mathrm{M} \mathrm{KCl}$ salt, respectively. These values show that the increase of the degree of dissociation $\alpha_{\text {diss }}$ above 0.5 may be a result of the effect of the dipole-dipole interaction and the density dependence of the dielectric constant $\varepsilon[50]$. 


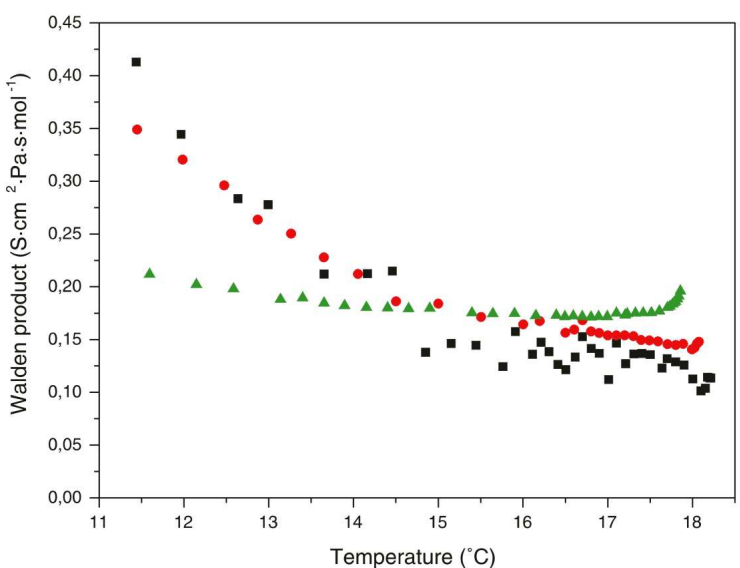

Fig. 3 Walden product as a function of temperature for the critical binary liquid TEA-Water with added $5 \times 10^{-4} \mathrm{M}, 10^{-3} \mathrm{M}$, and $5 \times 10^{-3} \mathrm{M}(\mathrm{KCl})$ salt

\subsubsection{Debye screening length}

According to the Restricted Primitive Model (RPM) which is based on the Debye-Hückel approximation [46], an electrolytic solution is considered as a collection of an equal number of charge-symmetric hard spheres of equal diameter $a$ in a structureless solvent with a dielectric constant $\varepsilon$. The Debye screening length is given by

$\lambda_{\mathrm{D}}=\left(\frac{\varepsilon_{0} \varepsilon k_{\mathrm{B}} T}{e^{2} C_{\alpha}}\right)^{1 / 2}$

where $e$ is the elementary charge, $\varepsilon_{0}$ is the vacuum permeability, $k_{\mathrm{B}}$ is Boltzmann's constant, $\varepsilon$ is the dielectric constant of the solvent, and $C_{\alpha}=2 N_{\mathrm{A}} C \alpha_{\text {diss }}$ with $N_{\mathrm{A}}$, the Avogadro's number, $C$, the molar concentration of salt, and $\alpha_{\text {diss }}$, the salt dissociation constant.

By using the value of the permittivity of the critical mixture $(\mathrm{TEA}-\mathrm{W}) \varepsilon=53.8$ introduced by Hamelin et al. at $1 \mathrm{MHz}$ [51] in Eq. (15), we have determined, at the temperature $T=17.857{ }^{\circ} \mathrm{C}$ (close to $T_{\mathrm{C}}$ ), the Debye screening length $\lambda_{\mathrm{D}}$ whose values are, respectively, $115.9 \AA, 93.6 \AA$, and $44.7 \AA$ for the investigated electrolytes $5 \times 10^{-4} \mathrm{M}, 10^{-3} \mathrm{M}$, and $5 \times 10^{-3} \mathrm{M} \mathrm{KCl}$ salt. It is well known that the Debye screening length value provides a good first estimate of the distance, beyond which Coulomb interactions can be essentially ignored, as well as the size of the region near a point charge, where opposite-charge counterions can be found. The obtained results indicate that the Debye length values decrease with increase in the salt concentration. This proves the weakness of the Coulomb interactions previously mentioned in such electrolyte solutions.

\section{Conclusion}

The shear viscosity and the electrical conductivity of the binary liquid mixture triethylamine-water (TEA-W) have been measured near the critical consolute point. For the pure system without $\mathrm{KCl}$ salt, the viscosity measurements yield an enhancement, as expected, for Ising criticality with a crossover to the regular behavior. Moreover, we have shown that, in a rather extended temperature range $t<10^{-3}$, the electrical conductivity exhibits a monotonous deviation from the VFT behavior described by a critical anomaly predicted by the shortrange fluctuation theory. This anomaly is described by a power law $t^{1-\alpha}$, where $t$ is the reduced temperature $\left|\frac{T-T_{\mathrm{C}}}{T_{\mathrm{C}}}\right|$ and $\alpha$ is the critical exponent of the specific heat anomaly at constant pressure. With added $\left(\mathrm{K}^{+}, \mathrm{Cl}^{-}\right)$ ions, the obtained values for the critical exponent $y$ associated with the viscosity anomaly are in the range of those of theoretical calculations for the Ising 3D universality class. By combining the viscosity and the electrical conductivity data of the electrolyte mixtures, the value of the computed Walden product has been determined, and the salt dissociation degrees $\alpha_{\text {diss }}$ and the Debye screening length have been estimated. The degree of dissociation $\alpha_{\text {diss }}$ of $\mathrm{KCl}$ salt in the critical binary fluid (TEA-W) is estimated near the critical temperature $T_{\mathrm{C}}$ : $\alpha_{\text {diss }}$ fluctuates from 0.62 to 0.92 . These free ion concentration values lead to the values of Debye screening length varying from 44.7 to $115.9 \AA$.

1. M. Bouanz, Phys. Rev. A 46, 4888 (1992).

2. M.E. Fisher, J. Stat. Phys. 75, 1 (1994).

3. G. Stell, J. Stat. Phys. 78, 197 (1995).

4. A. Toumi, M. Bouanz, and A. Gharbi, Chem. Phys. Lett. 362, 567 (2002).

5. E. Bloemen, J. Thoen, and W. Van Dael, J. Chem. Phys. 75, 1488 (1981).

6. M.R. Moldover, J.W. Cahn, 207, 1073 (1980).

7. O'D. Kwon, D. Beaglehole, W.W. Webb, B. Widom, B.J.W. Cahn, M.R. Moldover, and B. Stephenson, Phys. Rev. Lett. 48, 185 (1982).

8. A. Toumi, N. Hafaiedh, and M. Bouanz, Fluid Phase Equilibr. 278, 68 (2009).

9. N. Hafaiedh, A. Toumi, and M. Bouanz, J. Chem. Eng. Data. 54, 2195 (2009).

10. F. Kohler and O.K. Rice, J. Chem. Phys. 26, 1614 (1954).

11. J.N. Nayak, M.I. Aralaguppi, U.S. Toti, and T.M. Aminabhavi, J. Chem. Eng. Data. 48, 1483 (2003).

12. A. Hammadi and C.D. Champeney, J. Chem. Eng. Data. 45, 1116(2000). 
13. D. Nandi and D.K. Hazra, J. Ind. Chem. Soc. 80, 21 (2003).

14. V.K. Sayal, S. Chauhan, and P.K. Gupta, J. Ind. Chem. Soc. 79, 860 (2002) .

15. J.I. Bhat and C.B. Susha, Oriental. J. Chem. 19, 417 (2003).

16. A.C. Flewelling, R.J. DeFonseka, N. Khaleeli, J. Partee, and D.T. Jacobs, J. Chem. Phys. 104, 8048 (1996).

17. R. Behrends and U. Kaatze, Phys. Rev. E 68, 011205 (2003).

18. A. Ikehata, C. Hashimoto, Y. Mikami, and Y. Ozaki, Chem. Phys. Lett. 393, 403 (2004).

19. O.B. Ismailova, T.Kh. Akhmedov, Kh.T. Igamberdiev, Sh.I. Mamatkulov, A.A. Saidov, Sh.O. Tursunov, and P.K. Khabibullaev, J. Eng. Phys. Thermophys. 78, 1040 (2005).

20. R. Behrends, T. Telgmann, and U. Kaatze, J. Chem. Phys. 117, 9828 (2002).

21. S.I. Smadley. The Interpretation of the Ionic Conductivity in Liquids (Plenum, New York, 1980).

22. CRC Handbook of Chemistry and Physics, edited by David R. Lide (CRC Press, Boca Raton, FL, 2007).

23. P.C. Hohenberg and B.I. Halperin, Rev. Mod. Phys. 49, 435 (1977).

24. K. Kawasaki, Ann. Phys. NY. 61, 1 (1970).

25. R. Perl and R.A. Ferrell, Phys. Rev. Lett. 29, 51 (1972).

26. P. Das and J.K. Bhattacharjee, Phys. Rev. E 67, 036103 (2003) .

27. H. Hao, R.A. Ferrell, and J.K. Bhattacharjee, Phys. Rev. E 71, 021201 (2005).

28. F.J. Wegner, Phys. Rev. B 5, 4529 (1972).

29. D. Beysens, A. Bourgou, and G. Paladin, Phys. Rev. A 30, 2686 (1984).

30. D. Beysens, G. Paladin, and A. Bourgou, J. Phys. Lett. 44, 649 (1983).

31. M.E. Fisher and J.H. Chen, J. Phys. (Paris) 46, 1645 (1985).

32. J.V. Sengers, in Supercritical Fluids, edited by E. Kiran and J.M.H. Levelt (Kluwer, Dordrecht, 1994).

33. R.F. Berg and M.R. Moldover, J. Chem. Phys. 89, 3694 (1988).

34. J.C. Nieuwoudt and J.V. Sengers, J. Chem. Phys. 90, 457 (1989).

35. R.F. Berg, M.R. Moldover, and G.A. Zimmerli, Phys. Rev. E 60, 4079 (1999).

36. H. Vogel, Phys. Z. 22, 645 (1921).

37. C.A. Angell and E.J. Sare, J. Chem. Phys. 52, 1058 (1970).

38. C.A. Angell and R.D. Bressel, J. Phys. Chem. 76, 3244 (1972).
39. R.R. Nigmatullin, S.I. Osokin, and G. Smith, J. Phys.: Condensed Mat. 15, 3481 (2003).

40. H. Every, A.G. Bishop, M. Forsyth, and D.R. MacFarlane, Electrochim. Acta 45, 1279 (2000).

41. A. Oleinikova and M. Bonetti, Phys. Rev. Lett. 83, 2985 (1999).

42. M.E. Fisher and J.S. Langer, Phys. Rev. Lett. 20, 665 (1968).

43. M. Campostrini, A. Pelissetto, P. Rossi, and E. Vicari, Phys. Rev. E 60, 3526 (1999).

44. I. Nezbeda, J. Kolafa, in Ionic Soft Matter: Modern Trends in Theory and Applications, edited by D. Henderson et al. (Elsevier, Amsterdam, 2005), p. 83.

45. M. Bouanz and A. Gharbi, J. Phys. Condens. Matter 6, 4429 (1994).

46. P.P. Debye and F. Hückel, Phys. Z. 24, 185 (1923).

47. J. Barthel, L. Iberl, J. Rossmaier, H.J. Gores, and B. Kaukal, J. Solution. Chem. 19, 321 (1990).

48. L.C. Kenausis, E.C. Evers, and C.A. Kraus, Proc. Natl. Acad. Sci. U.S.A. 48, 121 (1962); 49, 141 (1963)

49. N. Ogata. J. Macromol. Sci. C 42, 399 (2002).

50. Y. Zhou, S. Yeh, and G. Stell, J. Chem. Phys. 102, 5785 (1995).

51. J. Hamelin, T.K. Bose, and J. Thoen, Phys. Rev. E 53, 779 (1996).

Received 31.12.10

ДОСЛІДЖЕННЯ ТРАНСПОРТНИХ ВЛАСТИВОСТЕЙ КРИТИЧНОЇ БІНАРНОЇ СУМІШ ТРИЕТИЛАМІН-ВОДА З ІОННОЮ ДОМШШКОЮ

A. Тумі, Н. Хафайе, М. Буанж

$\mathrm{P}$ е $з$ ю м е

Бінарна рідина триетиламіна і води має нижню точку розшарування при критичному складі з 32 масс.\% триетиламіну. Зсувна в'язкість $(\eta)$ і провідність $(\sigma)$ в однофазній області системи з додаванням іонів $\left(\mathrm{K}^{+}\right.$та $\left.\mathrm{Cl}^{-}\right)$у різних концентраціях були виміряні близько і далеко від критичної температури $T_{\mathrm{C}}$. Для системи без солі $\mathrm{KCl}$ виміри в'язкості показали очікуване збільшення ізингової критичності з переходом до регулярної поведінки. Дані зсувної в'язкості узгоджуються зі степеневою розбіжністю $\eta=\eta_{0}\left(Q \zeta_{0}\right)^{z} t^{-y}$, що передбачена теорією взаємодії мод і теорією динамічної ренормгрупи. В інтервалі температур $\Delta T=T_{\mathrm{C}}-T<2{ }^{\circ} \mathrm{C}$ провідність $(\sigma)$ показуе монотонне відхилення від теорії Фогеля-Фулчера-Тамманна. Ця аномалія описана степеневим законом $t^{1-\alpha}$, де $t$ - зведена температура $\left|\frac{T-T_{\mathrm{C}}}{T_{\mathrm{C}}}\right|$ і $\alpha-$ критичний індекс аномалії теплоємності в умовах сталого тиску. Для сумішей електролітів отримані критичні індекси узгоджуються з теоретичними результатами для тривимірної універсальності Ізинга. На основі даних із в'язкості і провідності визначено величину похідної Вальдена, ступінь дисоціації солі і дебаївський радіус екранування. 